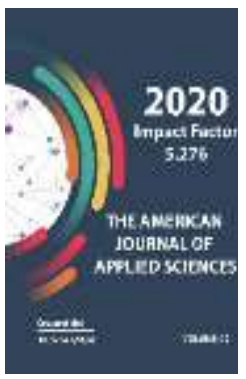

\title{
Development Of The Ability To See And Represent The Form Remotely In The Process Of Teaching Students To Portray A Creature In Higher Pedagogical Education
}

\author{
Botir Boltabaevich Baymetov \\ Professor, Chirchik State Pedagogical Institute, Uzbekistan
}

\begin{abstract}
Journal Website: http://usajournalshub.c om/index,php/tajas

Copyright: Original content from this work may be used under the terms of the creative commons attributes 4.0 licence.
\end{abstract}

\section{ABSTRACT}

The article introduces students to the method of using the theoretical laws of the visual arts to create works of art, students were provided with information on the formation of the ability to see and describe the shape of the body at a distance, history, theory, methodology of fine arts and the ancient stages of its development.

\section{KEYWORDS}

Fine art, painting, composition, artistic creation, vision, imagination, form, rhythm.

\section{INTRODUCTION}

Large-scale reforms carried out in our country create an excellent opportunity for our youth to actively communicate with their peers abroad in science, culture and other fields, to demonstrate their potential on a global scale. Therefore, pedagogical scientists working in our country pay special attention to the professional training of future teachers, the systematic development of their pedagogical skills. The sole purpose of all this is to ensure competitive training of modern personnel in the field of science and intellectual potential in Uzbekistan.

Today, qualified teachers who teach through creativity and innovative technology have a 
great responsibility. The above requirements have created the need to improve the pedagogical skills of future teachers in accordance with the requirements of the globalization process. The Action Strategy for the further development of the Republic of Uzbekistan for 2017-2021 identifies "continuous improvement of the quality and level of professionalism of teachers" [1] as one of the most important priorities for the integrated development of the higher education system.

The main task in teaching drawing is to form in this artist the ability to see and depict the shape of the body at a distance. Seeing and depicting the shape of an object from a distance (latitude) means seeing an object in "full size" in three dimensions (height, width and thickness).

The main task of the training is to be able to accurately represent nature in a way that accurately expresses its dimensions. This is achieved by developing the ability to measure with the eye (estimate distance and body dimensions in the eye) and focus the eye correctly. In such cases, it is important to develop visual acuity to determine body size and distance.

It is helpful to determine the ratio visually on a regular basis as you work in order to build judgment. Constant requirements for image accuracy teach future professionals to be attentive and responsible in their work, develop in them the skills of careful analysis of nature and at the same time develop the ability to remember the image they see.

Visual memory is one of the most valuable and compelling attributes of an artist. It maintains a clear and general idea of the shape, proportions, and structure of the body in the image. This makes it possible to draw a figure "from memory" based on imagination and understanding, and further facilitates the artist's work in creating independent compositions and sketches.

As a result of the constant practice of drawing from nature, people develop the ability to see and remember. Such exercises give good results, especially among young people who are just entering the art world. This system plays a key role in further strengthening the memory of the shape, construction, proportions, and plasticity of objects (obtained by sight) - the natural appearance of objects. To achieve this goal, short-term drawings and pictures are envisaged. In such exercises, which strengthen the visual memory, first the most important part is remembered, the secondary parts are negated; the main purpose is to remember the general form. The level of memory also expands and deepens during the exercise: secondary parts and fragments also remain in memory. Drawings and short-term pictures develop and nurture in the student the ability to see nature in a realistic way - to see fully.

In many cases, the young artist does not work in one order, pays more attention to its parts than to the general form, and does not understand the essence of each element. The work can be effective only if the student is able to see the image in its entirety and uses the principle of "from the general - to the parts and from the parts - to the general again". Constantly describing the parts with a common body allows you to control each part of the picture at the same time.

Determining the proportions of form and linear constructive structure using a barcode requires the artist to work on the entire painting at the same time. Much attention is paid to this principle in the tasks of depicting the human body, from simple still lifes to complex shapes.

It is possible to develop a certain amount of complete vision by mastering imaging skills. The success of the work done depends on how 
the student sits in front of the easel and in what position he holds the pen.

The student should hold the end of the pencil on the opposite side of the sharpened end. The pen can move at any angle on the paper. During the drawing process, the tip of the pencil is gently rubbed against the easel to ensure a firm position of the hand. This is accomplished by drawing the stripes parallel to each other at regular intervals to obtain the desired color. On spherical surfaces, the transition from dark to light is done by reducing or increasing the intervals between the bars and pressing the tip of the pencil harder or lighter.

It is known that a full-length body cannot be seen on the one hand. Only by looking around at each part of the body can one know the true shape of the body. The result of the ability to visualize and comprehend the latitudinal appearance of objects is the accurate depiction of the placed object. Therefore, using the boundaries and contours of the objects that are visible to us, we get an idea of the outer side of the body, taking into account the light falling on the body and the shadow that is formed. These features of visual perception define the rules of realistic fine art. In turn, a realistic image must have features that allow it to accurately visualize or understand the image, depending on the shape and color of the object.

Training in the fine arts begins with teaching how to observe objects in width. The main purpose of this is to be able to describe objects correctly. In realistic fine art, the shapes and objects that surround man are described as they exist in nature, and as they are perceived by the human eye. To do this, the student must master some features of visual perception, know the rules and methods of depicting the shape as a full-fledged on paper. As with all types and genres of fine art, the process of teaching pencil drawing involves the use of lessons in a simple-to-complex order. At the same time, if the previous lesson is not sufficiently mastered by the student, it will be difficult to understand the next, more complex tasks.

When teaching students to draw from life, memory and imagination, it is important to know the theoretical foundations of the principles of realistic visual arts.

For an accurate image of a body on the surface, the visible part of the body must combine all of the following characteristic features and characteristics: salinity, proportions, size, location of the material in space.

When we walk down the middle of the street and look out the windows, they seem to shrink. In fact, their size does not change. The parallel rail relays, when viewed from a distance, appear to be a point that joins towards the horizon, the wire logs shrinking as buildings, trees and people move away from us. At large distances, large-sized objects are flat and appear in the form of indistinct marks, lines, and fragments. Such a change of bodies is subject to certain laws. These laws arise as a result of human ability to see, the contraction of objects as a result of changes in distance. These are called the law of perspective in the fine arts.

Our perception of an object changes depending on the conditions (distance, size, weather, season, etc.) when we observe this object. The change in the shape of objects before our eyes is subject to clear perspective laws. Perspective reduction in the shape of distant objects is also found in ancient manuscripts.

The Italian artist Petro del Borgo, who lived and worked in the middle of the $\mathrm{XV}$ century, is considered to be one of the first representatives of this theory. Leonardo da Vinci also spoke about the laws of linear and spatial perspective in his "Scientific Article on Photography". The theoretical development of this law is also associated with the name of the 
German artist and theorist Albrecht Dyurer. A. P. Losenko and many other Russian artists learned from the theoretical aspects of perspective.

Below we will consider the laws that are crucial for the perspective compression of bodies. To do this, we must first have information about our organ of vision. It is known that light rays enter through the pupil of the eye, pass through the cornea (through a double-sided convex lens) and fall on the retina of the eye. The tiniest tubes of this membrane cause the nerve to be affected and transmit it to the brain, as a result of which we feel light. The light rays enter the eye in the form of a cone of light, and the cone is located at the top of the pupil.

When the distance changes, the scale of the body changes; when the body moves away from the eye, not only its width and height, but also its depth changes. The height and size of the body also decrease as a result of the change in width. Therefore, the size of a distant body appears to be uncertain relative to the size of a nearby body. When too far away from the eye, the objects generally shrink and appear flat without a line on the horizon. As objects get smaller, the distance between them also decreases. Things in the distance seem to be approaching and the space that separates them seems to have disappeared. As the distance between the objects and the eye increases further, the objects merge with each other to a point.

The perception of body shape is more dependent on a previously known body structure than on a perspective image. Therefore, when we see that parallel lines merge with each other as they move away, it is clear that the parallel lines in front of us can not intersect. In short, we see one thing, but we perceive it differently.

A drawing by an inexperienced artist is no different from a drawing of a small child - there is no perspective (all objects are depicted in only two dimensions), which, in turn, occurs due to ignorance of a realistic image. To clearly and distinctly show the contraction of the shape of the objects, we place a piece of rightangled glass a little farther away from ourselves, and watch a group of objects or silences through it. Before the light coming from the body hits the retina of our eye, it must pass at certain points on the surface of the mirror between the spectator and the body. Without changing the position of our head, we draw with a pencil or ink on the mirror along the contour of the visible body. The right perspective image is created in the window. In this case, the window serves as a drawing surface.

Depending on the location of the object (above or below the eye, far or near us) and the degree of rotation, the visible part of the object changes. Moving the body away from the eye causes it to shrink in size. Horizontal lines (straight corridors, railway tracks, etc.) move away from the eye and toward the conditional plane in front of the observer's eye: Objects above the eye shrink from top to bottom, and objects below the eye shrink from bottom to top. When the parallel horizontal lines are distant, they not only approach each other, but merge at one point.

Before drawing on the basis of nature, it is important to determine the position of the object relative to the horizon: it is necessary to determine whether it is below, above or below the horizon.

The horizon line will be at the height of the observer's eyes, therefore, when the artist's position changes, the position of the horizon line will also change. When an object is described in terms of a horizontal line, the visible part of the object changes: when objects above the horizon line are observed, the lower part of them and the upper part of those below the horizon are visible. When drawing in the open air, it is important to 
determine the angle of inclination of the horizontal lines moving towards the horizon and to express it correctly in the picture.

\section{CONCLUSION}

In conclusion, to learn how to draw threedimensional objects on paper, you first need to study the perspective structure of simple geometric shapes. The construction of the most complex bodies also results from the combination of simple bodies. The law of perspective structure of bodies can be easily mastered in the example of simple forms. Full mastery of drawing simple geometric shapes on the basis of the perspective rule allows you to draw any object in nature without any difficulties.

In order to master the principles of depicting a three-dimensional object on paper, it is important to place different objects in different ways relative to the horizon line several times, as well as rotate the images at different angles relative to the artist.

\section{REFERENCES}

1. Decree of the President of the Republic of Uzbekistan dated February 7, $2017 \mathrm{~N}$ PF-4947 "On the Action Strategy for further development of the Republic of Uzbekistan".

2. Boltaboevich, B. B. (2020). Formation of the skills of portraying the future teacher of fine arts in pencil drawing. ACADEMICIA: An International Multidisciplinary Research Journal, 10(5), 1122-1127.

3. Baymetov, B. B., \& Muratov, K. K. (2020). Self Sketches as a Tool in the Professional Training of a Future ArtistTeacher. Solid State Technology, 224231.

4. Байметов, Б. Б. (2016). История развития изобразительного искусства Узбекистана. Наука, образование и культура, (1 (4)).

5. Botir Boltabaevich Baymetov (2020). Art Of Modern Uzbekistan: The History Of Its Development During The Years Of Independence

6. The American Journal of Social Science and Education Innovations, Volume 02Issue 10-19, 125-132.

7. Boltabayevich, B. B., \& Shodievna, B. O. (2020). Individual Approach To The Formation Of Artistic And Creative Talents Of Students In Art Schools. The American Journal of Social Science and Education Innovations, 2(08), 637-642.

8. Boltaboyevich, B. B., \& Shokirjonugli, S. M. (2020). Formation of creative competences of the fine art future teachers describing geometrical forms (on sample of pencil drawing lessons). ACADEMICIA: An International Multidisciplinary Research Journal, 10(5), 1996-2001.

9. Boltabayevich, B. B, \& Pardaboy, K. (2020). SCIENTIFIC AND THEORETICAL ASPECTS OF THE FORMATION OF COMPOSITIONAL ABILITIES OF STUDENTS IN PAINTING CLASSES. European Journal of Research and Reflection in Educational Sciences Vol, 8(3).

10. Boltaboevich, B. B, \& Ogiloy, K. (2008). MASTER OF HISTORICAL PORTRAIT GENRE, A TEACHER WHO CREATED A SCHOOL IN THE FIELD OF FINE ARTS PEOPLE'S ARTIST OF UZBEKISTAN PROFESSOR MALIK NABIEV (19062008).

11. Baymetov, B. B., \& Sharipjonov, M. S. O. (2020). Development Of Students' Descriptive Competencies In Pencil Drawing Practice. The American Journal of Social Science and Education Innovations, 2(08), 261-267.

12. Boltabayevich, B. B., \& Shodievna, B. O. (2020). Individual Approach To The Formation of Artistic And Creative 
Talents Of Students In Art Schools. The American Journal of Social Science and Education Innovations, 2(08), 637-642.

13. Boltaboevich, B. B. (2020). Formation of the skills of portraying the future teacher of fine arts in pencil drawing. ACADEMICIA: An International Multidisciplinary Research Journal, 10(5), 1122-1127.

14. Sultanov Kh.E. Innovation technology clusters use of technology in illustration / International Journal of Psychosocial Rehabilitation, Vol. 24, Issue 04, 2020: ISSN: 1475-7192. P. 38713879;

15. Sultanov Kh.E., Sobirov S.T., Marasulova I..M. THEORETICAL BASIS OF CLUSTER APPROACH IN FINE ARTS EDUCATION / Journal of Critical Reviews ISSN- 2394-5125// Vol 7, Issue 9, 2020: -P. 108-111.

16. Omonov, Q., \& Karimov, N. (2020). Importance of Ancestoral Heritage. The American Journal of Social Science and Education Innovations, 2(09), 196202.

17. Boltabayevich, B. B., \& Shodievna, B. O. (2020). Individual Approach To The Formation of Artistic And Creative Talents Of Students In Art Schools. The American Journal of Social Science and Education Innovations, 2(08), 637-642. 